\title{
O historiador e a mídia: diálogos e disputas na arena da história pública
}

The Historian and the Media: Matches and Mismatches in the Field of Public History

Juliana Sayuri Ogassawara*

Viviane Trindade Borges ${ }^{\star *}, 1$

\section{Resumo}

Este artigo pretende discutir as relações entre o historiador e a mídia, da perspectiva da história pública. As autoras analisam o contexto de produção da série Guia Politicamente Incorreto, recentemente realizada pelo History Channel e inspirada no livro Guia Politicamente Incorreto da História do Brasil, do jornalista Leandro Narloch. Considera-se, aqui, a dimensão da história pública como esfera de divulgação do conhecimento histórico nas suas intersecções com outras áreas, como o jornalismo e a produção cinematográfica. Assim, busca-se enfatizar o papel público do historiador no tempo presente.

Palavras-chave: história pública; historiografia; mídia.

\begin{abstract}
This article intends to discuss the relationship between the historian and the media considering the perspective of public history. The authors analyze the context of production of the Brazilian TV Show Guia Politicamente Incorreto, recently produced by History Channel and inspired in the book Guia Politicamente Incorreto da História do Brasil, written by the journalist Leandro Narloch. In this text, we consider public history as a space of dissemination of historical knowledge in its intersections with other areas, such as journalism and film production. Therefore, we aim to highlight the public role of historians in the present time.

Keywords: public History; historiography; media.
\end{abstract}

\footnotetext{
* Universidade Federal de Santa Catarina (UFSC), Programa de Pós-Graduação em História, Florianópolis, SC, Brasil. julianasayuri@ymail.com <https://orcid.org/0000-0001-6186-5313>

** Universidade do Estado de Santa Catarina (Udesc), Laboratório de Patrimônio Cultural (Labpac), Florianópolis, SC, Brasil. vivianetborges@gmail.com <https://orcid.org/0000-0002-7576-7789>
} 
Na primavera parisiense de 2007, os medievalistas Colette Beaune, Ann Curry, François Michaud-Fréjaville, Olivier Bouzyl e Philippe Contamine foram convidados a conceder entrevistas para um documentário sobre a história de Joana D'Arc que seria transmitido no Arte, canal cultural prestigiado entre os acadêmicos na França.

Especialistas na trajetória da Donzela de Orléans, que até hoje inspira lendas e teses conspiratórias, os historiadores nem hesitaram em aceitar o convite: "No final das contas, a vocação acadêmica não é pesquisar por pesquisar, mas pesquisar para transmitir aos outros, seus colegas, seus estudantes e seus leitores", Beaune (2012, p. 9) escreveria depois.

As entrevistas foram filmadas na austera sala Labrousse da Biblioteca Nacional, em Paris. Segundo Beaune, os historiadores sabiam que não seriam "senhores" inteiramente de suas respostas, que seriam editadas para compor o documentário. O que os acadêmicos não sabiam é que o jornalista Marcel Gay também participaria do programa. Autor do polêmico livro L'Affaire Jeanne d'Arc ao lado do paleógrafo Roger Senzig, Gay instiga mitos sobre a heroína francesa queimada viva em maio de 1431: segundo suas teses, a camponesa ruiva faria parte de uma mirabolante conspiração da família real para manipular o destino da Guerra dos Cem Anos.

Em fins de março de 2008, às vésperas da estreia de Vraie Jeanne, Fausse Jeanne, dirigido por Martin Meissonnier, os historiadores descobriram que o filme seria lançado sob o selo de "docuficção", notavelmente ancorado no livro de Gay. A fim de conquistar um público maior, seria preciso, segundo sugeriu um jornalista envolvido na produção do documentário, "aceitar alguns arranjos com a verdade", conforme relatou a autora Colette Beaune na provocativa introdução intitulada "O historiador e a mídia: um mal-entendido", no livro Jeanne D’Arc: Vérités et Légendes:

O que fazer? Há um lado cômico nessa história. Servimos de caução intelectual, indispensáveis, mas insignificantes. Todos alinhados na obscuridade esverdeada de nossa cara biblioteca, eruditos quase ressecados no meio de nossos livros, procurávamos matizar nossas palavras, enquanto M. Gay foi filmado com cabelos ao vento, com o vale do rio Meuse ao fundo, a dizer a afirmações que, de qualquer forma, eram somente hipóteses. De um lado a imobilidade, do outro o movimento, de um lado os acadêmicos fora de moda e do outro o jornalista lutando contra o real... A imagem tem esse poder. (Beaune, 2012, p. 10) 
Em resposta ao episódio, os historiadores criticaram publicamente a impostura da produção do documentário no diário Le Figaro (Beaune et al., 2008). Ilustrativo, o caso francês desperta discussões sobre as possíveis relações entre história e mídia, marcadas por encontros, embates e tensões, que trazem implicações importantes para a divulgação do conhecimento histórico.

Temáticas históricas são frequentemente abordadas em diversas produções midiáticas, do jornalismo ao cinema, perpassando diferentes suportes de difusão de informações, perspectivas, temporalidades. Os avanços tecnológicos que se desenrolaram desde a década de 1970 até o boom da internet alavancaram a audiência de produções culturais audiovisuais como documentários e séries sobre temas históricos. Entretanto, a despeito da ampliação das audiências, tais produções muitas vezes são alvos de diversas críticas, especialmente feitas por acadêmicos, em relação a imprecisões factuais e abordagens amiúde superficiais da história (Ferreira, 2014). Entretanto, é preciso pontuar, outros autores criticam as tentativas de distinção entre uma história "séria" (produzida por historiadores de ofício) e uma história como mera forma de entretenimento, encontrada nos filmes históricos - estes últimos que, nas palavras de Robert Rosenstone (2010, p. 17), mesmo que diagnosticados como representações fantasiosas ou ideológicas em determinados casos, afetam a maneira como vemos o passado.

Nestas páginas discutiremos as relações entre história e mídia na prática da história pública. Compreende-se, como afirma assertivamente Sara Albieri (2011, p. 25), que é tempo de argumentar a favor da respeitabilidade das diversas formas de publicação histórica, para além dos periódicos e livros voltados à comunidade científica stricto sensu. Assim, apesar dos inúmeros avanços na construção do conhecimento em história e sua difusão, ainda permanecem velhos problemas, entre eles o "lento e desigual processo de divulgação dessa produção para o grande público” (Meneses, 2018, p. 160). Na mesma linha, entende-se que a história pública, ora "campo minado" de diversas questões, na expressão de Gerald Zahavi (2011, p. 56-57), não deve escapar a controvérsias sobre narrativas e interpretações históricas divergentes, mas buscar refletir sobre elas. Assim, pretende-se refletir sobre as possibilidades, os limites e os impasses atualmente afrontados por historiadores que buscam compartilhar conhecimento com audiências ampliadas mediante produções audiovisuais. A fim de explorar essas questões, analisaremos o contexto de produção da série Guia Politicamente Incorreto, realizada pelo History Channel no Brasil ao longo de 2017, que levantou discussões sobre usos públicos e apropriações políticas do passado. 
A princípio, é preciso considerar a dimensão da história pública voltada à difusão de conhecimento histórico dentro de uma lógica de ampliação de audiências, ultrapassando as bibliotecas e campi universitários ao ocupar outras frentes: cinema, literatura, museus, memoriais e séries de TV, em produções lideradas pelos próprios historiadores ou mediadas por outros profissionais (produtores, jornalistas e documentaristas, por exemplo). Essa dimensão parte de uma das chaves da história pública: a história para o público, remetendo a uma história voltada à difusão de conhecimento histórico dentro de uma lógica de ampliação de audiências e de ocupação de espaços para além da academia (Santhiago, 2016, p. 28). ${ }^{2}$

Data da década de 1970 a expressão public history, versada pelo historiador norte-americano Robert Kelley (1978), fundador da revista The Public Historian. Na primeira edição, publicada no outono californiano de 1978, Kelley define história pública como a atuação dos historiadores e do método histórico fora do âmbito acadêmico, como parte do processo público. A arena se firmou em países como Austrália, Canadá, Inglaterra, Itália e Nova Zelândia.

No Brasil, passou-se a discutir dimensões da história pública especialmente a partir da década de 1990, num contexto marcado por uma despertada demanda por memória após o fim da ditadura militar e o processo de redemocratização. O terreno contemporâneo permitiu florescer um diálogo fértil com disciplinas alinhadas a tais demandas, como história do tempo presente, história oral e história digital. No país, a história pública pode ser compreendida como estímulo para a reflexão e para "processo de autorreflexão por parte do pesquisador, capaz de dinamizar a revisão e a revitalização de seus princípios e práticas de pesquisa" (Santhiago, 2018, p. 290-294).

Na década presente, a temática ganhou mais visibilidade no país, diante das instaurações da Comissão Nacional da Verdade e da Lei de Acesso à Informação, em 2011, que tiveram impacto nas universidades, tanto na inclusão de novas fontes de informação nas investigações acadêmicas quanto na consciência da importância e interesse de sua divulgação - os dois marcos abriram portas para discussões sobre demandas sociais e desafios dos historiadores no estudo da história do tempo presente, do ponto de vista ético e político (Delgado; Ferreira, 2013).

À época estreou um curso introdutório de história pública na Universidade de São Paulo (USP), que ofereceu oficinas sobre fundamentos de divulgação científica, gerenciamento de arquivos e produção de podcasts, entre outros tópicos. Em 2012 se articularam a Rede Brasileira de História Pública e a Federação Internacional de História Pública. Aglutinando estudantes 
e profissionais de diversas áreas, como comunicólogos, cientistas sociais e produtores culturais, além de historiadores, o interesse crescente dinamizou a área, abrindo caminho para diversas iniciativas, entre encontros especializados, simpósios internacionais, oficinas, publicação de dossiês e coletâneas. Além do desenvolvimento de estudos de educação e mídia sobre a publicização do conhecimento histórico, discussões sobre os alicerces teóricos da história pública e a experimentação de novas linguagens e suportes, como apps, podcasts e webséries, se fizeram presentes além das rodas universitárias, na imprensa mainstream e iniciativas independentes.

A instalação de discussões da história pública abre caminhos certamente plurais, pois contempla diferentes modalidades, métodos e referenciais de uma rica literatura internacional, carregando consigo concepções diversas como prática, plataforma, movimento, disciplina, campo ou área de atuação de acordo com as tradições teóricas de tal ou qual núcleo universitário ou contexto político de determinado país. Trata-se de uma expressão elástica (Ashton, 2010). Território de fronteiras fluidas, a história pública abriga interpretações polissêmicas, configurando um "templo de tolerância", para citar a expressão da historiadora britânica Jill Liddington (2011).

Segundo Liddington, a prática da história pública corresponde à apresentação popular do passado para um leque de audiências, por intermédio de museus e patrimônios, filmes e ficções. Entretanto, como assinala a autora, a simplicidade da definição oculta a complexidade e desafios de um estudo que está intimamente relacionado à questão de como adquirimos nosso senso de passado, mediante memória e arquivos e, certamente, do modo como esses passados são apresentados publicamente - isto é, como é mediado nosso sentido de passado. Logo, trata-se não apenas de pensar na ampliação do público, mas também de ponderar a respeito daqueles que estão fazendo uso do passado e da maneira como este está sendo construído no presente. Assim, a história pública seria um movimento de difusão histórica e, ao mesmo tempo, de reflexão a respeito dessa difusão. Trata-se, ainda, não apenas dos atores e coadjuvantes de determinadas iniciativas de divulgação, mas do processo de construção das representações da história. Em outras palavras, como ironiza a autora, "estamos num terreno bem mais desafiador do que um mero clique no History Channel” (Liddington, 2011).

A fim de explorar essas trilhas, este texto foi segmentado em duas linhas. Na primeira, trataremos dos "diálogos", problematizando especificidades e pontos de encontro entre história e mídia na dimensão "história para o público" e 
as demandas sociais. Na seguinte, as "disputas" dão corpo às análises sobre as tensões entre historiador e mídia diante dos usos públicos do passado.

\section{DiÁlogos: DIVULGAÇÃO HISTÓRICA, MÍDIAS E MEDIAÇÕES}

À parte a diversidade deste campo, interessa-nos neste momento discutir os pontos de encontro entre a história e a mídia na dimensão "história para o público" que, conforme propõe o historiador Ricardo Santhiago, enfatiza a acessibilidade do conteúdo difundido em diversos estilos e suportes: literatura, jornalismo, cinema, artes visuais, museus, memoriais e TV, entre outros.

Nesse contexto, sinaliza-se um profissional responsável por produzir conteúdo histórico ativamente, ao passo que o público-alvo é identificado como leitor e/ou espectador de determinada produção cultural - mas, respondendo a uma crítica usual (Hilda, 2013), isso não quer dizer que se situe apenas como simples polo passivo no processo de comunicação midiática, uma vez que o leitor e/ou espectador é capaz de operar, segundo seus repertórios, suas próprias inferências, invenções e mediações (Martín-Barbero, 1997). Nesse processo, os produtores atuam segundo um conjunto de estratégias em que pesa a ideia de audiência e de consumo cultural, o que implica avaliar as linguagens adequadas para a inteligibilidade de determinado tópico ou a compreensão crítica de certos episódios históricos intrincados por um público leigo.

Qual é o papel possível do historiador profissional nessa dimensão da história pública atrelada à esfera midiática e às demandas sociais?

A atuação centrada nas necessidades do presente é permeada pelas críticas empreendidas em relação às possibilidades de se fazer uma história do tempo presente frente à falta de recuo temporal. A história, como disciplina que possui método próprio e uma prática regular de "decifrar documentos", levaria à necessidade de objetividade e de distanciamento dos problemas do presente, como se somente o intervalo temporal garantisse a possibilidade de crítica. Tal crítica tornou-se um diferencial importante dos historiadores do tempo presente, pois sendo contemporâneo de seu objeto e dividindo com ele as mesmas referências, o historiador teria uma melhor compreensão da realidade estudada (Chartier, 1993). Assim, o que era um inconveniente transformou-se num trunfo, abrindo novos caminhos para o estudo da história do século XX (Ferreira, 2000, p. 7).

A noção de afastamento temporal, conforme apontamos, é tributária da história metódica, e decorre disso sua centralidade em documentos escritos, as fontes escritas e oficiais, tidas como mais confiáveis, e com critérios de 
acesso bem definidos por questões legais. Assim, a história do tempo presente surge como parte da "renovação historiográfica provocada pela crise do estruturalismo, possibilitando, por um lado, evoluções significativas nos campos político, social e cultural e, por outro, a emergência da história do tempo presente e da história pública" (Joffily; Borges, 2018). Essa mudança implica, entre outros pontos, uma nova concepção da ideia de fonte histórica, centrada não apenas no documento de arquivo, mas na polissemia das mais variadas manifestações da criação humana. O desejo dos historiadores de aproximar a história de seus públicos não é novo, aliás: remete, por exemplo, aos Annales, pela participação de historiadores em programas de TV que tentaram popularizar a história nas décadas de 1970 e 1980 (Barbosa, 2016).

A priori, há diferentes atuações para o historiador se compreendermos a história pública como uma possibilidade de atingir o público não especializado com o conhecimento histórico, respeitando as regras metodológicas do métier e explorando diversos recursos tecnológicos. Assim, tal atitude metodológica não implica o "abandono de procedimentos preocupados com a seriedade e o caráter analítico na busca de uma produção de conhecimento marcada por compromissos éticos e profissionais". Não sugere, portanto, uma oposição ao debate acadêmico, mas sim uma contribuição para alargar seus horizontes (Rovai, 2018, p. 188).

Atualmente, de um lado, o historiador pode desempenhar o papel de profissional produtor e divulgador de determinado conhecimento histórico (por exemplo, enquanto autor de uma investigação científica e, ao mesmo tempo, editor de um portal que busque disseminar tal conteúdo) - isto é, neste caso não há mediação de outrem. Também é possível considerar a atividade de indivíduos de áreas afins, interessados e dedicados a difundir conhecimento histórico com especial ênfase às linguagens (por exemplo, um jornalista que se dedique a publicizar digitalmente arquivos relacionados à ditadura militar, como os Arquivos da Ditadura, página na qual Elio Gaspari reúne documentos desde a década de 1980).

De outro lado, o historiador pode ser consultado como fonte para reportagens, documentário ou filme de ficção, revista de divulgação científica ou almanaque de curiosidades, quer seja como referência intelectual para fomentar discussões relevantes quer seja como argumento de autoridade para os propósitos da produção. À diferença dos modelos anteriores, esse contexto implica mediação de um profissional de outra ordem (um produtor ou um jornalista, por exemplo), um processo que traz implicações significativas desde o momento da entrevista (a formulação das perguntas, as orientações 
ocasionais sobre o tom das respostas), passando pela edição (declarações pinçadas e argumentos fragmentados, a depender da linha editorial e dos baldrames ideológicos e políticos da "casa") e chegando até a divulgação do produto final (uma situação que desperta para a imprevisibilidade das apropriações das considerações conferidas durante a entrevista). Trata-se, portanto, de uma relação assimétrica.

É essa intrincada arena que nos interessa nesta discussão, um ponto de encontro que muitas vezes provoca embates e tensões. Isso porque, é preciso lembrar, os olhares e objetivos do historiador e do jornalista (ou diretor, documentarista, produtor) não necessariamente estão alinhados - o que se traduz, por exemplo, nas diferentes construções de narrativas. Enquanto produtores, jornalistas e editores não raro buscam construir uma narrativa linear que faça sentido para não iniciados num conflito histórico X, o trabalho historiográfico compreende explorar lacunas e contradições, rupturas e continuidades que talvez não façam sentido à primeira vista para o espectador e/ ou leitor leigo. Além disso, é possível refletir sobre a dimensão do anacronismo, uma armadilha na qual tanto jornalistas quanto historiadores podem cair nos usos da história no contexto do entretenimento. Rompendo pontes entre passado e presente em razão de incompreensão, informações imprecisas e descontextualizadas de uma margem à outra, o anacronismo, diz Bloch, é o mais imperdoável pecado ao olhar de uma ciência do tempo (Bloch, 2001, p. 144).

Idealmente, se é preciso dizer, historiadores e jornalistas lidam com a mesma matéria-prima (a informação), a fim de oxigenar o intercâmbio de ideias, envolver a sociedade civil e contribuir criticamente para o debate público, se possível a partir de princípios democráticos e do potencial educativo e emancipatório da informação. Fora das demarcações imaginárias do mundo ideal, porém, há uma série de interferências e interesses (de ordem política, econômica, cultural) capazes de desequilibrar a informação entre a simplificação didática e a simples distorção.

O debate "história \& jornalismo", que protagoniza discussões a respeito da história pública, é muito mais complexo e não pode ser reduzido a uma simples dicotomia. Santhiago assinala nessa arena a rejeição de historiadores ao trabalho de história pública feito por outros profissionais:

Aventureiros, marqueteiros, oportunistas: os 'outros' (os jornalistas, principalmente) costumam ser retratados assim, de saída, em textos e falas - geralmente, em falas - que não são fruto de análise, mas de juízos de valor marcados por uma redefinição valorativa do significado de história pública. Juízos, em geral, meto- 
dologicamente mal conduzidos: Eduardo Bueno e Leandro Narloch não são os melhores exemplos, nem os exemplos mais representativos, de jornalistas que têm produzido obras de cunho histórico; são somente os jornalistas que melhor servem a esse fim deslegitimador. (Santhiago, 2016, p. 29-30)

Não buscamos enveredar estas páginas, portanto, a uma polarização "historiadores versus jornalistas”, mas pensar possibilidades de diálogos a fim de enriquecer uma discussão complexa. Se norteado por princípios éticos e honestidade intelectual, o encontro entre historiadores e jornalistas é frutífero para ambos - e principalmente para o público. Entretanto, os desencontros (disputas, discordâncias de matriz metodológica e desentendimentos éticos) são fenômenos sintomáticos do teor tenso e assimétrico desse relacionamento, revelando diferentes estratégias para publicar, publicizar ou simplesmente polemizar a história. A eles dedicaremos as linhas seguintes.

\section{DISPUTAS: INFORMAÇÃO, TRANSPARÊNCIA E USOS DO PASSADO}

No Brasil, tensões entre historiador e mídia afloraram ao longo da década de 1990, diante da profusão de biografias no mercado editorial escritas por jornalistas - alguns autores conquistaram a crítica e o público, ficando mais festejados que historiadores de ofício (Schmidt, 1997). Tais tensões se tornaram mais nítidas a partir dos anos 2000, nas comemorações e efemérides como os 500 anos do "descobrimento" do Brasil.

Indicadores diversos à época (como minisséries ancoradas em questões de fundo histórico e revistas voltadas para divulgação histórica) sinalizavam a crescente demanda da sociedade por história. Lembrado por uma programação diversa, de séries do arqueólogo egípcio Zahi Hawass, reconstituições de batalhas da Segunda Guerra Mundial e especiais dispostos a elucidar "mistérios" (Fonseca, 2016, p. 192-193), o próprio History Channel, presente em mais de 125 países, incluindo o Brasil, pode ser entendido como sintoma dessa crescente demanda: em 2013, citam Anita Lucchesi e Bruno L. P. de Carvalho (Carvalho; Lucchesi, 2016, p. 149), estudo da empresa estadunidense especializada BrandIndex indicou que o History Channel era a quarta marca mais amada pelo público norte-americano, ficando atrás apenas de Ford, Amazon e Subway. O fenômeno político, econômico e cultural em torno do passado catapultou o lançamento de revistas de história, produção de documentários e expansão da literatura memorialística, entre outros. Efeitos da síndrome de 
memória que atravessa o tempo presente, em que "o passado está vendendo mais do que o futuro" (Huyssen, 2000).

No Brasil, jornalistas, publishers e publicitários encontraram um novo nicho de mercado ao constatar que o passado poderia representar "bons negócios" (Malerba, 2014). Assim, tal demanda foi paulatinamente preenchida por profissionais vindos de outros campos além do campus.

Não tardaram as críticas, endereçadas especialmente à qualidade questionável da história escrita por não historiadores. À diferença de um método histórico interpretativo, analítico e crítico, predominaram narrativas históricas anedóticas, factuais, às vezes romantizadas, outras dramatizadas com requintes pitorescos - um tipo de narrativa alinhado às ideias de faits divers e feature, jargões jornalísticos que remetem a acontecimentos desconexos de historicidade e atraem atenções apenas por seu caráter inusitado (Malerba, 2014, p. 32).

No entanto, ao abordar os nichos de ação de historiadores estadunidenses, Olivier Dumoulin aborda criticamente a dimensão da public history que resvala a uma "empreitada global de deslocamento do papel social do historiador", englobando novas funções públicas como arquivistas e gestores de arquivos, consultores, conservadores, documentaristas e produtores de filmes, editores, advocates e policy advisors - ocupações cuja emergência, na interpretação de Dumoulin, estaria relacionada à crise de desemprego de jovens historiadores ante um mercado universitário em recessão. O autor critica o papel do historiador a serviço de agências, empresas particulares ou órgãos oficiais na condição de expert, contratado para desenvolver projetos. Para Dumoulin (2017, p. 85-89), ao invés de priorizar a ideia de público, o historiador se dobraria a serviço de determinado cliente.

A despeito das críticas, o estilo de alguns livros de história feitos por não historiadores funcionou no mercado: com proposta "didática", estrutura de saga, estilo coloquial e ênfase nos detalhes psicológicos dos personagens históricos (julgados como heróis ou vilões nessas tramas), essa história essencialmente événementielle catapultou diversos títulos a best-sellers. Nestas páginas destacamos os Guias.

Lançado em 2009, o Guia Politicamente Incorreto da História do Brasil, do jornalista Leandro Narloch, foi um dos mais emblemáticos - e mais criticados, com repercussões políticas até o presente. Lembramos Ricardo Santhiago (2016, p. 29) ao afirmar que Eduardo Bueno e Narloch não são os melhores exemplos de jornalistas-autores de obras de cunho histórico: são apenas os jornalistas que melhor servem a propósitos de deslegitimação da história pública. ${ }^{3}$ Contudo, o que nos interessa são as tensões entre o métier do historiador 
e a mídia, nos seus usos públicos do passado e, nesse contexto, o trabalho dos autores citados traz exemplos emblemáticos.

Foi essa a moldura para o affair History Channel. Intelectuais como os historiadores Lira Neto, Isabel Lustosa, Mary Del Priore, o jornalista Laurentino Gomes ${ }^{4}$ e a antropóloga Lilia Schwarcz foram abordados pela produtora Studio Fly em 2017. O estúdio os convidou a participar de "um especial sobre história do Brasil". Os convites foram aceitos.

Em fevereiro, Lira Neto recebeu o produtor Matheus Ruas na sua casa, em São Paulo. Antes de iniciar a gravação da entrevista, Ruas pediu a Lira Neto que respondesse às questões como se estivesse conversando com Homer Simpson, o pai-protagonista aparvalhado da série Os Simpsons, um tipo de símbolo de mediocridade intelectual e indolência. O historiador estranhou, mas respondeu às perguntas didaticamente, apesar de certa "indignação interior".

Em fins de outubro, na véspera da estreia do programa, Lira Neto descobriu que seu depoimento fora incluído em uma nova série intitulada Guia Politicamente Incorreto, baseada no controverso Guia Politicamente Incorreto da História do Brasil, de Leandro Narloch, que foi repórter da revista Veja e editor das revistas Aventuras na História e Superinteressante, da Editora Abril.

Alvo de críticas de diversos historiadores profissionais desde seu lançamento, pelo simplismo de seus argumentos e pela ausência de críticas fundamentadas, o Guia se propõe a narrar uma história do Brasil desvencilhada da historiografia "politicamente correta", na expressão do autor. Assim, afirma pretender provocar e polemizar, apresentando uma pequena coletânea de histórias "irritantes e desagradáveis". O modelo dos Guias, vale lembrar, surgiu nos Estados Unidos em 2004, com o volume Politically Incorrect Guide to American History, do historiador revisionista Thomas E. Woods Jr., e virou "febre" entre os norte-americanos. "Todos se orientam pelo princípio de se contraporem ao que identificam como discursos politicamente corretos da historiografia, apresentados como conteúdos ideologizados a serem desmascarados" (Meneses, 2018, p. 179).

Todavia, apesar das críticas, o Guia Politicamente Incorreto da História do Brasil vingou nas livrarias. Em 2011, o livro teve sua edição ampliada. Na sequência foram lançados outros títulos a compor a trilogia do autor: Guia Politicamente Incorreto da América Latina (2011), ao lado do jornalista Duda Teixeira, e Guia Politicamente Incorreto da História do Mundo (2013). O sucesso de vendas é expressivo: junto aos demais volumes (América Latina e Mundo), o trabalho vendeu mais de um milhão de exemplares, ocupando a 
lista dos dez livros mais vendidos no Brasil na categoria não ficção entre 2009 e 2013 (Meneses, 2018, p. 174).

Ao descobrir a vinculação de seu depoimento com a série de Narloch, Lira Neto criticou publicamente a falta de informação da produtora Studio Fly, que definiu mediante as expressões "arapuca" e "armadilha". Formado em jornalismo, além de filosofia e letras, o escritor é familiarizado com as engrenagens das redações, das quais se afastou desde 2001 para se dedicar aos livros. Premiado biógrafo de Getúlio Vargas, entre outros personagens históricos, o historiador afirmou se sentir "ludibriado" pelos produtores. "Se tivesse sido informado disso [da inclusão na série] previamente, não teria concedido a entrevista. Considero tais livros um desserviço ao público jovem, alvo prioritário deles. São simplórios na argumentação, falaciosos na utilização das fontes, pródigos em promover estereótipos e sedimentar preconceitos contra minorias historicamente marginalizadas", Lira Neto criticou na sua coluna dominical na Folha de S. Paulo.

Outras fontes, como Isabel Lustosa, Lilia Schwarcz, Laurentino Gomes e Mary Del Priore, também manifestaram publicamente críticas à falta de transparência da produção, nos seus perfis nas mídias digitais (Facebook e Twitter) ou em declarações à imprensa que noticiou o episódio (Folha de S. Paulo, O Globo e O Estado de S. Paulo, por exemplo).

Lira Neto e outros autores pediram a retirada de suas participações do programa. Na sua página no Facebook, Narloch se disse "frustrado", mas afirmou compreender o mal-estar dos entrevistados e endossou as demandas, que foram atendidas a tempo pelo History, canal cultural integrante da joint venture A+E Networks América Latina, cuja matriz é norte-americana.

Contudo, [Leandro Narloch] alegou, tudo havia sido feito em nome de promover "um debate elegante sobre temas delicados". Quem assistiu aos primeiros episódios constatou que não há elegância ou debate naquilo. A presença e o nome de pesquisadores sérios estão sendo utilizados, na edição, apenas para legitimar e corroborar uma narrativa tendenciosa, "politicamente incorreta". Por si só, a palavra "guia", do título, não deixa margem para dúvidas: sugere condução, viés, predefinição de rumo. [...] Os recursos gráficos irônicos e a edição das falas feitas pelo diretor da série confundem, de propósito, o bom humor com o deboche, a informação com o entretenimento, o debate de ideias com o polemismo raso. Por meio de linguagem moderninha, vendem velhas ideias. Em um único momento, pelo menos, houve sinceridade: quando o diretor me disse que o público-alvo deles era o Homer Simpson. (Lira Neto, 29 out. 2017) 
Ao analisar a série, é compreensível o descontentamento de Lira Neto e sua negativa para a produção audiovisual, que caminha pari passu ao livro de Narloch. Participar da série, afinal, seria legitimar e corroborar a narrativa "politicamente correta" proposta pelos livros do autor, servindo-lhe de "caução intelectual”, para resgatar a expressão de Colette Beaune.

No ar entre 21 de outubro e 9 de dezembro de 2017, a série foi apresentada pelo youtuber Felipe Castanhari, um vlogger influente na internet, que mobiliza mais de 10 milhões de seguidores no YouTube. Foram feitas dezenas de entrevistas para compor o programa, contando com fontes como os jornalistas Eduardo Bueno (autor da trilogia Terra Brasilis), Laurentino Gomes (autor dos best-sellers 1808 e 1822), Reinaldo José Lopes (autor de 1499), o historiador e comentarista da Jovem Pan Marco Antonio Villa, o filósofo Luiz Felipe Pondé e o músico Lobão. Segmentada em oito capítulos de cerca de 45 minutos, a série documental é marcada por edição irreverente, animações gráficas, trilha sonora pop e um tom de humor debochado - uma linguagem que se quer atraente para o público jovem.

Se no livro Narloch cita a historiografia disponível (seja para corroborar seus próprios argumentos, seja para criticá-la quando dela discorda), na série a narrativa é conduzida por outros elementos (artes gráficas e intervenções pretensamente cômicas do youtuber e do autor) que eclipsam os depoimentos fragmentados das fontes. No entanto, o tom é similar: sob o selo "politicamente incorreto", o livro e a série trazem uma visão conservadora sobre a história do Brasil, disseminando preconceitos contra índios e negros, por exemplo, ao desengavetar uma interpretação retrógrada ao representar os colonizadores europeus como paladinos do processo civilizatório nas Américas.

Frente a essas escolhas, fica claro que os usos do passado se inserem em uma construção de sentidos conflituosa, permeada por disputas, seleção e demandas sociais (Borges, 2017). Segundo a crítica do historiador Jurandir Malerba (2014, p. 41), a tais narrativas não importa contar a história, mas impor princípios morais a partir do que se considera certo ou errado politicamente - e o autor apenas retoma uma escrita histórica antiga, alegórica e a-científica, "garimpando na historiografia episódios picarescos que corroborem suas posições”. E, segundo a análise da historiadora Márcia Elisa Teté Ramos (2015), o autor emprega estratégias textuais para criar efeitos de proximidade com o leitor (o vocativo "você" ao longo do livro, por exemplo), de legitimidade (alegando usar a historiografia da vertente da nova história para embasar seus argumentos) e de atualidade (a fim de transmitir a impressão de novidade e, portanto, de relevância editorial, contrapõe-se ao que designa uma perspectiva 
"ultrapassada" da história). Na interpretação de Narloch, os historiadores seriam profissionais influenciados por discursos e ideologias "de esquerda" que reproduziriam ideias e concepções "defasadas".

$\mathrm{Na}$ série, a produção aposta em estratégias semelhantes, o que é visível logo no episódio de estreia: a informalidade do narrador Felipe Castanhari (que tenta forjar intimidade com o espectador, tratado como "amigo" e "galera”), a autoridade atribuída aos variados historiadores e fontes (na proposta de ouvir outros lados e opiniões diferentes que, na expressão coloquial do youtuber, se traduzem em "tretas") e de novidade (na proposta de apresentar a história do país de uma maneira inédita, "diferente").

Os tempos "pré-descobrimento" e o período colonial são abordados no primeiro episódio. Tal como no livro, a série martela ideias de que os indígenas eram selvagens salvos pela bússola do progresso dos brancos europeus. Insiste no argumento anacrônico, presente no livro, da falta de consciência ecológica entre os indígenas: segundo o autor, eles só não desmataram as florestas inteiramente, pois as áreas verdes eram imensas - se fossem menores, eles as teriam destruído. Ainda segundo sustenta a série do autor, foram os portugueses que "ensinaram" os povos nativos a preservar a floresta. Indicamos esses erros analíticos e o anacronismo presente nas obras de Narloch, mas compreendemos que, ao analisar uma produção fílmica, o historiador não deve se limitar a uma simples enumeração de erros e acertos em relação ao período histórico representado na tela, mas analisar como o passado foi contado e, principalmente, por que foi contado com base em tal narrativa (Rosenstone, 2010).

No formato documentário, por exemplo, lembrado por Raymond Williams (2011, p. 97-98), há uma mediação de diretores, diretores de fotografia, roteiristas e repórteres que selecionam e apresentam algo ao público, culminando em uma superposição entre o informe factual e a apresentação dramática das edições. Mas, se muitas vezes essa superposição não é clara, suas consequências negativas o são a olhos atentos, como a distorção dos acontecimentos e a difamação de indivíduos.

Em estudo realizado com 138 estudantes de um colégio de Londrina (PR), a historiadora Márcia Elisa Teté Ramos diagnosticou que um número significativo de alunos concordou com as teses do livro de Leandro Narloch sobre a época da colonização, reforçando as representações do indígena como atrasado, indolente e inadequado à civilização capitalista. Uma das conclusões do estudo indica que o livro (um produto da cultura midiática moldado ao universo cultural dos jovens) é mais aceito pelos alunos e, principalmente, mais convincente a eles, do que o conhecimento histórico tradicionalmente transmitido pelos professores 
nas salas de aula. Nesse contexto, vale lançar uma questão ainda mais inquietante: que perspectivas teriam os jovens diante da série, uma produção mais dinâmica e visualmente mais atraente do que o livro?

Passíveis de críticas, obviamente, as produções fílmicas são dotadas de um efeito de realidade intenso, que provoca outros efeitos além do texto escrito. Nesse sentido, os historiadores não devem ignorá-los, mas investigar os motivos que levam a tal situação.

Na sua coluna de 13 de dezembro de 2017 na Folha de S. Paulo, dias após o encerramento da série, Leandro Narloch provocou:

Historiadores brasileiros produziram obras excelentes nos últimos anos, mas o trabalho de encontrá-las equivale ao do britânico que pretende escavar um lixão na tentativa de recuperar um disco rígido com 7.500 bitcoins. Para achar uma boa história, o interessado precisa enfrentar amontoados de estudos com abstrações incompreensíveis, palavras envelhecidas e frases cheias de resíduos descartáveis. Muitos professores se ressentem comigo e outros jornalistas que escreveram best-sellers de história do Brasil. [...] Muita pompa e pouca habilidade - eis uma causa do estilo entediante dos historiadores. Acreditam que escrever em bom português exige utilizar palavras antigas. [...] Tudo bem que o objetivo de autores acadêmicos não é vender milhares de cópias, e sim comunicar descobertas aos colegas. Mas um pouco de clareza sempre ajuda na argumentação - e evita que os estudos apodreçam nos aterros de teses e dissertações das universidades. (Narloch, 13 dez. 2017)

Talvez por estratégia de marketing, autores como Narloch e Bueno insistam em afirmações agressivas e equivocadas como essa. Entretanto, interessa-nos neste momento não a rivalidade trivial entre historiadores e jornalistas, como exemplifica o trecho citado, mas discutir a dinâmica relação entre os profissionais que pretendem explorar novas linguagens a fim de desengavetar o conhecimento histórico das bibliotecas universitárias. Trata-se, mais do que uma querela de historiadores versus jornalistas, de uma discussão sobre a formação da consciência histórica na disseminação do conhecimento (Malerba, 2014; Malerba, 2017), as instâncias de legitimação de tal conhecimento e as disputas que se impõem em casos emblemáticos como evidencia a série do History Channel.

Os dilemas que cercam os usos do passado e sua publicação trazem velhas questões já problematizadas na virada para o século XX por Seignobos, como preservar a escrita da história para os especialistas que dominavam as regras 
do métier, e ao mesmo tempo produzir manuais de vulgarização voltados ao grande público (Charle, 1990; Ferreira, 2012). Seria mais que "saber falar, no mesmo tom, aos doutos e aos escolares”, privilégio de alguns eleitos, segundo atestou Marc Bloch (2001, p. 41), mas questionar como atingir um público maior sem abrir mão do méthode historique e ainda usando diferentes "tons", para diferentes públicos? Tal situação evidencia a complexa relação que "o historiador, como todo ator social, mantém com a legitimação de sua atividade, com sua justificativa para fazer parte do corpo social" (Dumoulin, 2017, p. 17).

\section{CONSIDERAÇÕES FINAIS: O PAPEL PÚBLICO DO HISTORIADOR NO TEMPO PRESENTE}

Ao propor um posicionamento politicamente incorreto em relação às narrativas históricas, tanto a série quanto o livro Guia Politicamente Incorreto da História do Brasil polarizam duas perspectivas: de um lado, os professores de história que seriam sempre "de esquerda" e, assim, ensinariam uma história “ideológica” ou partidária; de outro, estariam os defensores de uma história hipoteticamente livre de tais amarras - não por acaso, nos últimos tempos avançaram iniciativas como o programa Escola Sem Partido (Penna; Aquino, 2016; Penna, 2017), que defende princípios de "neutralidade" nas salas de aula, e que indica, aliás, como leitura os Guias de Leandro Narloch (Ramos, 2016).

A fim de lapidar uma reflexão sobre esses fenômenos a partir da história pública, é preciso compreender que essas representações impactam o conhecimento histórico que circula no cotidiano. Pensando nas possibilidades, limites e impasses confrontados por historiadores nessa esfera, três questões entrecruzadas se impõem: a mediação, a linguagem e o papel público do historiador no tempo presente.

Decerto a escrita da história não é prerrogativa exclusiva de apenas uma ou outra confraria literária, mas é preciso privilegiar a crítica na história pública a fim de preservar o que faz dela propriamente história. Impõe-se aí a problemática da mediação - e, conforme interpreta o historiador alemão Jörn Rüsen, a mediação muitas vezes é necessária para tornar palatável a produção de uma disciplina especializada da história profissional (Rüsen, 2010). Se, por um lado, vale investir na solicitude para entrevistas e apostar nas possibilidades de mediação a partir de produções culturais que envolvem outros profissionais, como uma série de TV, por outro é preciso considerar que a palavra final ficará com o mediador - os historiadores não mais seriam "senhores" de suas 
respostas, para lembrar a medievalista francesa Colette Beaune. Instaura-se um impasse: conceder entrevistas a uma produção de qualidade questionável, mas que é capaz de atingir milhões, ou recusar participações por desavenças ideológicas? Ocupar a mídia mainstream, ou ignorá-la?

A respeito da participação de intelectuais na TV, Pierre Bourdieu propõe interrogações prévias para encontrar as respostas a tais questões. O sociólogo diz não acreditar que se possa abordar algo profundo na TV, especialmente sobre a própria lógica da TV. Entretanto, pondera: "Se é verdade que não se pode dizer nada na televisão, eu não deveria concluir, com certo número de intelectuais, de artistas, de escritores, entre os maiores, que deveríamos abster-nos de nos exprimir nela? Parece-me que não se tem de aceitar essa alternativa absoluta, em termos de tudo ou nada. Creio que é importante ir falar na televisão, mas sob certas condições" (Bourdieu, 1997, p. 15, grifo no original):

Com a televisão, estamos diante de um instrumento que, teoricamente, possibilita atingir todo mundo. Daí certo número de questões prévias: o que tenho a dizer está destinado a atingir todo mundo? Estou disposto a fazer de modo que meu discurso, por sua forma, possa ser entendido por todo mundo? [...] Há uma missão dos pesquisadores, dos cientistas em particular - e talvez ela seja particularmente urgente no que se refere às ciências da sociedade -, que é a de restituir a todos as contribuições da pesquisa. Somos, como dizia Husserl, "funcionários da humanidade", pagos pelo Estado para descobrir coisas, seja sobre o mundo natural, seja sobre o mundo social, e, ao que me parece, faz parte de nossas obrigações restituir o que descobrimos. Sempre me esforcei por passar minhas aceitações ou minhas recusas pelos crivos dessas interrogações prévias. E desejaria que todos aqueles que são convidados a ir à televisão as fizessem a si mesmos ou que fossem pouco a pouco obrigados a fazê-las porque os telespectadores, os críticos de televisão, as fazem a si próprios e as fazem a propósito de suas aparições na televisão: ele tem algo a dizer? Está em condições de poder dizê-lo? O que ele diz merece ser dito nesse lugar? Em uma palavra, que faz ele ali? (Bourdieu, 1997, p. 18)

A essas questões, acrescentamos outras. Se fazer história pública significa atuar a favor da difusão de conhecimento histórico para amplas audiências (Almeida; Rovai, 2011), os historiadores teriam como garantir o respeito às práticas científicas da história nessas produções? Esse movimento de "garantir" não implicaria uma tentativa de regulação, que iria exatamente contra a inspiração inicial de amplos segmentos da própria história pública? 
A fundo na análise do caso proposto, ponta de iceberg de diversos outros questionamentos, é possível afirmar que o caso do History Channel envolve eixos diferentes, mas relacionados. Primeiro, a falta de transparência da produtora Studio Fly, que omitiu informações essenciais ao convidar os intelectuais a participar da série documental. Segundo, o vínculo da série com o controverso livro de Leandro Narloch. A mediação foi corrompida e, conforme criticou Lira Neto, na edição final dos capítulos, a presença de pesquisadores importantes foi utilizada como chancela intelectual para dar ares de legitimidade a uma narrativa "politicamente incorreta" do autor.

A despeito de certos disparates e deliberadas distorções das fontes históricas, os Guias são produtos da cultura midiática e, ao mesmo tempo, integrantes de uma história pública. Ao lado da historiadora Márcia Elisa Teté Ramos, é preciso destacar, porém, que a forma de produção de materiais midiáticos como os Guias não é encorajada na universidade. Dito isso, convém pensar quais tipos de materiais midiáticos atualmente correspondem aos interesses dos historiadores (como autores ou fontes).

Há, sim, diferenças estruturais entre as formas de apresentação para leigos e para acadêmicos - e a história pública deve atentar para as adaptações do discurso acadêmico para outros tipos de linguagem, dialogando inclusive com outras disciplinas, buscando soluções que fujam da mera simplificação. No caso do History Channel, a problemática da linguagem é evidente, e pode ser analisada com base em três pontos.

Primeiro, a definição do perfil do público-alvo da série, segundo o produtor Matheus Ruas: Homer Simpson, anti-herói amarelado inventado pelo cartunista norte-americano Matt Groening. ${ }^{5}$ Lançar mão de uma linguagem simplista presumindo certa imbecilidade do público é não só uma atitude arrogante: favorece abordagens superficiais e abre brechas para um polemismo improdutivo, implicando o empobrecimento do debate público.

Segundo, há diferenças sensíveis entre a simplificação didática da linguagem e a distorção de fatos para privilegiar argumentos frágeis e até falsos. A série e o livro Guia Politicamente Incorreto da História do Brasil caminham pela última trilha. Aos historiadores profissionais fica o desafio de encontrar equilíbrios linguísticos a fim de ampliar suas audiências sem abrir mão do rigor metodológico - um desafio que não necessariamente se vence por critérios mercadológicos (publicar um best-seller, por exemplo), mas por pilares de difusão democrática do conhecimento a diversos setores da sociedade.

Terceiro, à diferença dos historiadores franceses do affaire Marcel Gay, que recorreram a duas mídias tradicionais para lançar suas críticas após a 
estreia do “docuficção” sobre Joana D’Arc (uma carta no diário Le Figaro e um livro), os historiadores "ludibriados" pelo Studio Fly se manifestaram imediatamente nas mídias digitais, nos perfis pessoais no Facebook e no Twitter: apropriando-se da visibilidade da internet, imediata e veloz, eles pautaram a imprensa, que passou a reportar o caso e pressionar os produtores, culminando na retirada de seus depoimentos da série antes de sua estreia. É um exemplo simples, mas evidencia como há territórios tecnológicos, plataformas e linguagens a explorar que passam ao largo da mídia mainstream.

Em tempos marcados por demandas sociais e discussões políticas a quente, sobretudo relacionadas ao ensino e às práticas didáticas, salta aos olhos o papel público do historiador. A compreensão do fenômeno contemporâneo de demanda social por historiografia se beneficiaria de abordagens que considerem a inserção da historiografia dentro do campo mais amplo da cultura contemporânea (Malerba, 2014, p. 43). Um convite irrecusável se impõe nesse contexto: assumir a importância da dimensão pública da atividade dos historiadores, ultrapassando os muros institucionais da universidade, e usar a palavra, como intelectuais, nos debates públicos.

Faz parte da história pública experimentar mediações, inovar linguagens, propor novas formas de contar uma narrativa histórica que mobilize atitudes, críticas e reflexões em torno de diferentes formatos e temas. A isso compreendemos que é preciso combinar um compromisso ético, educativo e sociopolítico, que favoreça o acesso a informações e a divulgação do conhecimento histórico como parte da cultura contemporânea.

\section{FONTES}

LIRA NETO. Eticamente incorretos. Folha de S. Paulo, 29 out. 2017. Ilustrada, p. 8. NARLOCH, Leandro. Guia Politicamente Incorreto da História do Brasil. 2. ed. São Paulo: Leya, 2011.

NARLOCH, Leandro. Por que historiadores escrevem tão mal? Folha de S. Paulo, 13 dez. 2017. Disponível em: https://goo.gl/ZqNWtL. Último acesso em: 24 jan. 2018.

\section{REFERÊNCIAS}

ALBIERI, Sara. História pública e consciência histórica. In: ALMEIDA, Juniele R.; ROVAI, Marta G. de Oliveira (org.). Introdução à História Pública. São Paulo: Letra e Voz, 2011. p. 19-28. 
ALMEIDA, Juniele R.; ROVAI, Marta G. de Oliveira (org.). Introdução à História Pública. São Paulo: Letra e Voz, 2011.

ASHTON, Paul. Introduction - Going Public. Public History Review, v. 17, p. 1-15, 2010.

BARBOSA, Marialva. Imprensa e história pública. In: ALMEIDA, Juniele R.; MAUAD, Ana Maria; SANTHIAGO, Ricardo (org.). História Pública no Brasil: sentidos e itinerários. São Paulo: Letra e Voz, 2016. p. 121-131.

BEAUNE, Colette. Joana D’Arc: verdades e lendas. Rio de Janeiro: Cassará, 2012.

BEAUNE. Colette; BOUZY, Olivier; CONTAMINE, Philippe; MICHAUD-FRÉJAVILLE, Françoise. Jeanne D’Arc et les impostures. Le Figaro, Paris, 30 avril 2008. Disponível em: https://goo.gl/CHDPZn. Último acesso em: 23 jan. 2018.

BLOCH, Marc. Apologia da história. Rio de Janeiro: Jorge Zahar, 2001.

BOURDIEU, Pierre. Sobre a televisão. Rio de Janeiro: Jorge Zahar, 1997.

BORGES, Viviane T. Memórias difíceis: a reforma psiquiátrica brasileira e os usos políticos de um passado doloroso. Museitec-Museologia, Tecnologia e Patrimônio Cultural, Sergipe, v. 10, p. 105-127, 2017.

CARVALHO, Bruno L. Pastor de; LUCCHESI, Anita. História digital: reflexões, experiências e perspectivas. In: ALMEIDA, Juniele R.; MAUAD, Ana Maria; SANTHIAGO, Ricardo (org.). História Pública no Brasil: sentidos e itinerários. São Paulo: Letra e Voz, 2016. p. 149-164.

CHARLE, Christophe. Naissance des intelectuels: 1880-1890. Paris: Ed. de Minuit, 1990. CHARTIER, Roger. A história cultural. Rio de Janeiro: Bertrand Brasil, 1993.

DELGADO, Lucília de A. Neves; FERREIRA, Marieta de Moraes. História do tempo presente e ensino de história. História Hoje, São Paulo: Anpuh, v. 2, n. 4, p. 19-34, 2013.

DUMOULIN, Olivier. O papel social do historiador. Belo Horizonte: Autêntica, 2017. FERREIRA, Marieta de Moraes. Demandas sociais e história do tempo presente. In: VARELLA et al. (org.). Tempo presente e usos do passado. Rio de Janeiro: Ed. FGV, 2012.

FERREIRA, Marieta de Moraes. História do tempo presente: desafios. Cultura Vozes, Petrópolis, v. 94, n. 3, p. 111-124, maio/jun. 2000.

FERREIRA, Rodrigo de A. História pública e cinema: o filme Chico Rei e o conhecimento histórico. Estudos Históricos, Rio de Janeiro, v. 27, n. 54, p. 275-294, jul./dez. 2014.

FONSECA, Thais Nívia de L. e. Ensino de história, mídia e história pública. In: ALMEIDA, Juniele R.; MAUAD, Ana Maria; SANTHIAGO, Ricardo (org.). História Pública no Brasil: sentidos e itinerários. São Paulo: Letra e Voz, 2016. p. 185-194. HILDA, Kean. Introduction. In: KEAN, Hilda; MARTIN, Paul (org.). The Public History Reader. London: Routledge, 2013. 
HUYSSEN, Andreas. Seduzidos pela memória: arquitetura, monumentos, mídia. Rio de Janeiro: Aeroplano, 2000.

JOFFILY, Mariana; BORGES, Viviane. A história do tempo presente e outros campos da história. In: ELIBIO JUNIOR, Antonio M. et al. Tempo presente: uma história em debate. Rio de Janeiro: Ágora: Multifoco, 2018. [No prelo].

KELLEY, Robert. Public History: Its Origins, Nature, and Prospects. The Public Historian, v. 1, n. 1, p. 16-28, 1978.

LIDDINGTON, Jill. O que é história pública? Os públicos e seus passados. In: ALMEIDA, Juniele R.; ROVAI, Marta G. de Oliveira (org.). Introdução à História Pública. São Paulo: Letra e Voz, 2011. p. 31-52.

MALERBA, Jurandir. Acadêmicos na berlinda, ou como cada um escreve a História? Uma reflexão sobre o embate entre historiadores acadêmicos e não acadêmicos no Brasil à luz dos debates sobre Public History. História da Historiografia, Ouro Preto, n. 15, p. 27-50, ago. 2014.

MALERBA, Jurandir. Os historiadores e seus públicos: desafios ao conhecimento histórico na era digital. Revista Brasileira de História, São Paulo: Anpuh, v. 37, n. 74, p. 135-154, 2017.

MARTÍN-BARBERO, Jesús. Dos meios às mediações. Rio de Janeiro: Ed. UFRJ, 1997. MENESES, Sônia. Livros, leitores e internautas: os guias da história e os embates pelo passado através da mídia. In: ALMEIDA, Juniele R. de; MENESES, Sônia (org.). História Pública em debate: patrimônio, educação e mediações do passado. São Paulo: Letra e Voz, 2018.

PENNA, Fernando. Escola Sem Partido como ameaça à educação democrática: fabricando o ódio aos professores e destruindo o potencial educacional da escola. In: MACHADO, André Roberto; TOLEDO, Maria Rita de A. (org.). Golpes na história e na escola. São Paulo: Cortez: Anpuh-SP, 2017.

PENNA, Fernando; AQUINO, Renata. As operações que tornam a história pública. In: ALMEIDA, Juniele R.; MAUAD, Ana Maria; SANTHIAGO, Ricardo (org.). História Pública no Brasil: sentidos e itinerários. São Paulo: Letra e Voz, 2016.

RAMOS, Márcia Elisa T. O que pensam os alunos do ensino médio sobre o ensino de história apresentado no Guia Politicamente Incorreto da História do Brasil de Leandro Narloch. Diálogos, Maringá, v. 19, n. 1, p. 345-367, 2015.

RAMOS, Márcia Elisa T. O mau professor de história segundo os Guias Politicamente Incorretos de História. Fronteiras, Dourados, v. 18, n. 31, p. 99-122, jan./jun. 2016.

ROSENSTONE, Robert. A história nos filmes, os filmes na história. São Paulo: Paz e Terra, 2010.

ROVAI, Marta. Publicizar sem simplificar: o historiador como mediador ético. In: ALMEIDA, Juniele R. de; MENESES, Sonia (org.). História Pública em debate: patrimônio, educação e mediações do passado. São Paulo: Letra e Voz, 2018. 
SANTHIAGO, Ricardo. Duas palavras, muitos significados: alguns comentários sobre a história pública no Brasil. In: ALMEIDA, Juniele R.; MAUAD, Ana Maria; SANTHIAGO, Ricardo (org.). História Pública no Brasil: sentidos e itinerários. São Paulo: Letra e Voz, 2016. p. 23-36.

SANTHIAGO, Ricardo. História pública e autorreflexividade: da prescrição ao processo. Tempo e Argumento, Florianópolis, v. 10, n. 23, p. 286-309, jan./mar. 2018. SCHMIDT, Benito Bisso. Construindo biografias - historiadores e jornalistas: aproximações e afastamentos. Estudos Históricos, Rio de Janeiro, v. 10, n. 19, p. 3-21, 1997. WILLIAMS, Raymond. Televisión: tecnología y forma cultural. Buenos Aires: Paidós, 2011.

ZAHAVI, Gerald. Ensinando história pública no século XXI. In: ALMEIDA, Juniele R. de; ROVAI, Marta G. de Oliveira (org.). Introdução à História Pública. São Paulo: Letra e Voz, 2011. p. 53-63.

\section{NOTAS}

${ }^{1}$ A autora Viviane Trindade Borges é bolsista de Produtividade em Pesquisa 2 do CNPq.

${ }^{2}$ Ricardo Santhiago assinala quatro engajamentos fundamentais, passíveis de entrecruzamento, na história pública: história feita para o público (que prioriza a ampliação de audiências); a história feita com o público (de caráter colaborativo); a história feita pelo público (que assimila formas não institucionais de história e memória); e história e público (que abarca a reflexividade e autorreflexividade do campo).

${ }^{3}$ Não temos a intenção de desqualificar os autores e certamente existem diferenças importantes na abordagem realizada pelos dois jornalistas citados: Eduardo Bueno trabalha com uma abordagem por vezes anacrônica, mas atenta a questões factuais; já Leandro Narloch procura, na abordagem voltada ao "politicamente incorreto", principalmente chocar o público por meio de afirmações sensacionalistas e muitas vezes em comprometimento factual.

${ }^{4}$ Jurandir Malerba lembra que há ótimos historiadores sem formação universitária na área, como Evaldo Cabral de Mello e Alberto da Costa e Silva, e historiadores com formação acadêmica escrevendo história popular, como Mary del Priore. Lembra o autor, ainda, que há referências entre jornalistas como Ruy Castro, Fernando Morais, Zuenir Ventura, Elio Gaspari e Juremir Machado, por um lado, "ou por um Laurentino Gomes, um Eduardo Bueno ou um Narloch, por outro - esses três últimos, aliás, tão diversos entre si. Os dois primeiros são apenas produtores de histórias anódinas, de pouco fôlego analítico, de baixa complexidade; o último, autor de uma história ruim e perniciosa, reacionária" (MALERBA, 2014, p. 43). Entretanto, no episódio analisado nestas páginas, Gomes sai do balaio de Narloch, endossando críticas à falta de transparência da produtora contratada pelo History Channel.

${ }^{5}$ Não foi a primeira vez, vale lembrar, que Homer foi utilizado como exemplo de espectador médio do noticiário: em 2005, durante uma visita de professores universitários às ins- 
talações do Jornal Nacional, o mais importante programa jornalístico da TV Globo, o editor William Bonner definiu sua audiência como alguém com dificuldade de compreender informações mais complexas. Quem relatou o caso foi o sociólogo e jornalista Laurindo Lalo Leal, da Universidade de São Paulo, na revista Carta Capital.

Artigo recebido em $1^{\circ}$ de junho de 2018. Aprovado em 16 de agosto de 2018. 